2010

Recognizing Creative Leadership: Can Creative Idea Expression Negatively Relate to Perceptions of Leadership Potential?

Jennifer S. Mueller

University of Pennsylvania

Jack Goncalo

Cornell University, jag97@cornell.edu

Dishan Kamdar

Indian School of Business

Follow this and additional works at: http://digitalcommons.ilr.cornell.edu/articles

Part of the Business Commons

This Article is brought to you for free and open access by the ILR Collection at DigitalCommons@ILR. It has been accepted for inclusion in Articles and Chapters by an authorized administrator of DigitalCommons@ILR. For more information, please contact hlmdigital@cornell.edu. 


\title{
Recognizing Creative Leadership: Can Creative Idea Expression Negatively Relate to Perceptions of Leadership Potential?
}

\begin{abstract}
Drawing on and extending prototype theories of creativity and leadership, we theorize that the expression of creative ideas may diminish judgments of leadership potential unless the charismatic leadership prototype is activated in the minds of social perceivers. Study lshows creative idea expression is negatively related to perceptions of leadership potential in a sample of employees working in jobs that required creative problem solving. Study 2 shows that participants randomly instructed to express creative solutions during an interaction are viewed as having lower leadership potential. A third scenario study replicated this finding showing that participants attributed less leadership potential to targets expressing creative ideas, except when the "charismatic" leader prototype was activated. In sum, we show that the negative association between expressing creative ideas and leadership potential is robust and underscores an important but previously unidentified bias against selecting effective leaders.
\end{abstract}

Keywords

creativity, leadership, person perception

\section{Disciplines}

Business

\section{Comments}

\section{Suggested Citation}

Mueller, J. S., Goncalo, J. A. \& Kamdar, D. (2010). Recognizing creative leadership: Can creative idea expression negatively relate to perceptions of leadership potential? [Electronic version]. Retrieved [insert date], from Cornell University, School of Industrial and Labor Relations site:

http://digitalcommons.ilr.cornell.edu/articles/340/

\section{Required Publisher Statement}

Final version forthcoming as: Mueller, J. S., Goncalo, J. A. \& Kamdar, D. (in press). Recognizing creative leadership: Can creative idea expression negatively relate to perceptions of leadership potential? Journal of Experimental Social Psychology. 
Running Head: CREATIVITY AND LEADERSHIP PERCEPTIONS

Recognizing creative leadership:

Can creative idea expression negatively relate to perceptions of leadership potential?

Jennifer S. Mueller

University of Pennsylvania

Jack A. Goncalo

Cornell University, ILR

Dishan Kamdar

Indian School of Business

\section{In Press, Journal of Experimental Social Psychology}


Recognizing creative leadership:

Can creative idea expression negatively relate to perceptions of leadership potential?

\begin{abstract}
Drawing on and extending prototype theories of creativity and leadership, we theorize that the expression of creative ideas may diminish judgments of leadership potential unless the charismatic leadership prototype is activated in the minds of social perceivers. Study 1 shows creative idea expression is negatively related to perceptions of leadership potential in a sample of employees working in jobs that required creative problem solving. Study 2 shows that participants randomly instructed to express creative solutions during an interaction are viewed as having lower leadership potential. A third scenario study replicated this finding showing that participants attributed less leadership potential to targets expressing creative ideas, except when the "charismatic" leader prototype was activated. In sum, we show that the negative association between expressing creative ideas and leadership potential is robust and underscores an important but previously unidentified bias against selecting effective leaders.
\end{abstract}

KEYWORDS: Creativity, leadership, person perception 
Recognizing creative leadership:

Can creative idea expression negatively relate to perceptions of leadership potential?

According to a recent survey of 1,500 chief executives conducted by IBM's Institute for Business Value, CEOs identify "creativity," the ability to generate novel and useful solutions, as the most important leadership competency for the successful organization of the future (Kern, 2010). Creative leadership allows leaders to move organizations in profitable new directions, a view supported by management research showing that leaders with creative ability are more effective at promoting positive change and inspiring their followers than leaders who lack creative ability (House \& Howell, 1992; Mumford \& Connelly, 1991; Mumford, Marks, Connelly, Zaccaro, \& Reiter-Palmon, 2000; Shin \& Zhou, 2003; Shin \& Zhou, 2007; Sternberg, 2007; Tierney, Farmer, \& Graen, 1999; Yukl, 1989). However, by integrating the prototype theory of leadership and creativity, we investigate one potential roadblock organizations may face on the way to realizing this new vision of creative leadership. We propose that people who express creative solutions may be viewed as having lower levels of leadership potential because stereotypes of "creative people" and "effective leaders" may sometimes clash in the minds of social perceivers.

Prototypes are pre-existing knowledge structures that reflect expectations about the average characteristic held by people or objects in a given category (Rosch, 1978). For example, the most readily accessible prototype of a bird is the characteristic ability to fly, and birds that match this prototype are quickly and easily categorized as such while flightless birds require more time and effort to categorize correctly (Rosch, 1973). A similar psychological process underlies perceptions of leadership. The most prototypical kind of leader is expected to organize 
and coordinate groups to diminish uncertainty and promote order by emphasizing shared goals (Philips \& Lord, 1981). The prototypical leader is also expected to conform to group norms and goals in order to symbolically support the group identity (van Knippenberg, van Knippenberg, De Cremer, \& Hogg, 2004) and to promote collective action (Lord, Foti, \& de Vader, 1984). Targets who behave in ways that convey these characteristics to others are readily categorized as fitting the leadership prototype.

Research on prototypes of the creative individual underscores that social perceivers most often diagnose creative potential based on targets' expression of creative ideas in social contexts (Elsbach \& Kramer, 2003). However, far from matching fundamental leadership expectations associated with exuding control and promoting clear goals, the expression of creative solutions may actually introduce ambiguity or uncertainty, in part, because by definition, novel ideas involve deviations from the status quo and are not yet proven (Amabile, 1996; Staw, 1995). Prototype theory confirms this view that the expression of creative ideas is often associated with uncertainty, nonconformity, unorthodoxy, and unconventionality (Elsbach \& Kramer, 2003; Sternberg, 1985) - traits which run contrary to deeply rooted expectations that prototypical leaders diminish uncertainty and provide normative order (Phillips \& Lord, 1981).

This is not to say, however, that creative idea expression and leadership will always be at odds in the minds of social perceivers. Indeed, categorization theory suggests the leadership prototype is multi-faceted and may include less central components that shape perceptions of leadership only when they are made salient (Lord et al, 1984). Charismatic leadership in particular represents one category of leadership that includes second order characteristics like uniqueness and individualism which may be more compatible with prototypes of creative people (Den Hartog, House, Hanges, Ruiz-Quintanilla, \& Dorfman, 1999). Indeed, the prototype of 
creativity actually includes “charisma” (Elsbach \& Kramer, 2003; Goncalo, Flynn \& Kim, 2010). Hence, when the charismatic prototype is activated in the minds of evaluators, the expression of creative solutions may actually send a clear signal of leadership potential.

We test our prediction in three studies using multiple manipulations and measures of creativity and leadership. The first two studies provide evidence that expressing creative ideas resulted in lower perceptions of leadership. In a third study, we replicated these findings and extended them by investigating the moderating effect of the charismatic leadership prototype.

\section{Study 1}

Participants: The participants included 346 employees (291 targets and 55 raters) working within a single division of a large multi-national refinery in central India. Employees were engaged in tasks which required creativity. This company explicitly encouraged creativity of its employees through explicit formal statements as well as informal management practices. Employees were mostly male $(74 \%)$, with a mean age of approximately $32($ s.d. $=6.10)$ years, 5 $($ s.d. $=2.95)$ years of organizational tenure, and $70 \%$ had a bachelors degree or higher.

Procedure: Target participants completed questionnaires asking them to assess their and demographic variables and intrinsic motivation (response rate $=68 \%$ ). Raters completed questionnaires asking them to assess targets' leadership potential and creative idea expression (response rate $=80 \%$ ). With the exception of the demographic variables (age, organizational tenure, sex, education), all measures involved a rating scale with anchors from 1 (strongly disagree) to 7 (strongly agree).

Raters assessed the extent to which targets produced creative (i.e., novel and useful) ideas employing a 3-item scale developed by Oldham \& Cummings (1996). $(\alpha=.91)$. Targets also completed a 4-item measure of leadership potential. Instructions asked targets to rate the extent 
to which this person has the potential to: "become an effective leader," "learn leadership skills," "advance to a leadership position," and "become a role-model for his/her current coworkers," $(\alpha$ $=.92$ ). A single rater rated each target's creativity and leadership potential.

We also included a control for intrinsic motivation to investigate the possibility that creative people are not viewed as leaders because they are so interested and absorbed in their work (Amabile, 1985) that they neglect interpersonal activities (e.g., leadership activities) to focus exclusively on their own tasks (Rothbard \& Wilk, 2010). Target participants rated their own intrinsic motivation using a 5-item measure adapted from Grant (2008). $(\alpha=.87)$.

We employed SAS PROC mixed to test the association between perceptions of creativity and leadership potential, and centered all major variables (Hofmann \& Gavin, 1998). Table 1 shows Pearson correlation coefficients of all major variables.

\section{Results}

We ran a single multi-level model controlling for team level random variance and including intrinsic motivation as well as sex, organizational tenure, education and age as controls to explore the relationship between rater's perceptions of creativity and leadership potential. This multi-level model controlled for gender $(\gamma=-.40, t(229)=-2.12, p<.05)$, organizational tenure $(\gamma=.00, t(229)=.07, p=.94)$, education $(\gamma=.11, t(229)=.99, p=.32)$, age $(\gamma=.01$, $t(229)=.50, p=.61)$, and intrinsic motivation $(\gamma=.17, t(229)=3.03, p<.01)$, showing that perceptions of creative performance did negatively and significantly relate to perceptions of leadership potential $(\gamma=-.15, t(229)=-2.62, p<.01)$.

Study 2 
In the next study, we sought to replicate Study 1 using an experimental design. Hence in Study 2 we randomly assigned participants to pitch a creative (novel and useful) or a useful idea to an evaluator who rated their leadership potential.

\section{Method}

Participants: The participants were 194 students enrolled in a large northeastern university in the United States; $50 \%$ were male (mean age $=21.1$ years, $\mathrm{SD}=3.71$ ). Students were assigned to same sex dyads $(n=97)$.

Procedure: Participants were randomly assigned either to the role of an idea pitcher or evaluator; pitchers were assigned to one of two conditions and given 10 minutes to: 1) prepare a creative (novel and useful) or 2) a useful (but not novel) solution to the following question: "What could an airlines do to obtain more revenue from passengers?" Evaluators were instructed to rate another participant's ability to contribute to a group project by addressing the question above in a creative way. Pitchers were then paired with evaluators to describe their idea in a 10 minute observation period, during which time evaluators were instructed to merely observe pitchers' responses. Subsequently, evaluators rated pitchers on several dimensions, including leadership potential using a 3-item scale: "How much leadership would this applicant exhibit?", "How much control over the team's activities would this member exhibit?", "I think the applicant is an effective leader." $(\alpha=.86)$. We also included evaluators' ratings of each pitcher's idea creativity, novelty and usefulness as a manipulation check (Alphas $=.90:$ All items were rated on a 7-point scale (anchors: $1=$ none/not at all, $7=$ extremely, very much so). Table 2 shows the descriptive statistics of all major variables. We wanted to rule out the possibility that people who express creative ideas are simply viewed negatively, even on dimensions unrelated to leadership potential. Therefore, we also asked evaluators to rate pitchers on their competence 
(using a 3-item scale including: competence, capable, and intelligent) and warmth (using a 3item scale including: warmth, likability, sincerity), two fundamental dimensions of person perception (Cuddy, Fiske, \& Glick, 2007). The Alpha coefficients for both scales exceeded .80.

\section{Results}

An independent t-test confirmed that pitchers instructed to generate creative ideas expressed ideas that were judged by evaluators to be significantly more creative $(M=4.50)$ than pitchers in the useful condition $(M=3.74 ; t=1.96, p<.05)$. However, as instructed, ideas pitched by subjects were viewed by evaluators as equally useful in the creative $(M=4.40)$ and useful condition $(M=4.95 ; t=-1.56, p=n s)$. We used ANOVA to test our hypothesis that ratings of leadership potential would be lower in the creative versus the useful condition. Table 3 shows the ANOVA results controlling for sex of dyad, that pitchers instructed to generate creative ideas $(M=3.90)$ were assessed by evaluators as having significantly less leadership potential than pitchers instructed to generate useful ideas $(M=4.46)$.

Additional analyses also revealed that evaluators viewed pitchers in the creative condition $(\mathrm{M}=4.99)$ as equally competent as pitchers in the useful condition $(M=5.29 ; t=-$ $1.22, p=n s)$. An independent t-test also revealed that evaluators viewed pitchers in the creative condition $(M=5.12)$ as equally warm as pitchers in the useful condition $(M=5.23 ; t=-.48, p=$ $n s)$. In sum, these results suggest that the negative relationship between creative idea expression and evaluations of leadership potential is probably not due to a negative halo associated with creative idea expression.

\section{Study 3}

Studies 1 and 2 provide converging evidence that expressing creative ideas diminishes attributions of leadership. We theorized that the underlying psychological mechanism explaining 
this effect involved a lack of fit between the content of the creativity and the leadership prototype that is chronically accessible to our participants. To test this mechanism, we exposed participants to a leadership prototype which research proposes is compatible with creativity. Specifically, charismatic leaders are prototypically viewed as nonconformist and unique (Den Hartog et al., 1999). This suggests that if the charismatic (as opposed to non-specific) leader prototype were primed, then expressing creative ideas would match the expectations about how charismatic leaders behave and result in a positive association with leadership. Therefore, in study 3 we utilize moderation to examine the mechanism and manipulate the content of the leadership prototype directly (Spencer, Zanna, \& Fong, 2005).

\section{Method}

Participants: The participants were 183 students enrolled in a large northeastern university in the United States; $39 \%$ were male (mean age $=20.68$ years, SD $=2.98$ ).

Procedure: The study design consisted of a 2 (charismatic prototype: activated versus not activated) x 2 (idea: novel and useful (creative) versus useful) between-participants factor design. Participants were assigned randomly to conditions. In phase 1 of the experiment, the charismatic leadership prototype was activated by asking participants to list five attributes that describe a charismatic leader. Conversely, in the condition where charismatic leadership was not activated, participants were asked to list five attributes of a leader. To remain consistent with prior experimental research of the leadership prototype (Lord et al., 1984), we did not define leadership or charismatic leadership for participants in phase 1. To ensure that the prototype content activated in the charismatic leader condition was different from the content activated in the leadership condition, we gave three blind and independent coders the mostly widely used definition of charismatic leadership (House \& Howell, 1992; Howell \& Frost, 1989), and asked 
them to rate the extent to which each participant's overall response fit the definition of charismatic leadership. Coders used a 7 point scale with 7 being "strongly agree" and 1 being "strongly disagree" $(\mathrm{Alpha}=.86)$. An independent t-test revealed that the descriptors generated by participants in the charismatic leadership condition matched the charismatic prototype $(\mathrm{M}=$ 4.0) significantly more than participants in the leadership activation condition $(\mathrm{M}=2.19 ; \mathrm{t}=$ $4.52, \mathrm{p}<.01)$. In phase 2 , participants read and responded to a scenario in which they were asked to evaluate a potential team member for a task which encouraged creativity based on their written response to a strategic problem. To vary the two conditions for high and low novelty (holding usefulness constant) we chose two ideas derived from Study 2, which were pretested to show significant differences in novelty $\left(\mathrm{M}_{\text {creative idea }}=5.32, \mathrm{M}_{\text {useful idea }}=2.72 ; t=10.76, p<.01\right)$, but not usefulness $\left(\mathrm{M}_{\text {creative idea }}=3.73, \mathrm{M}_{\mathrm{useful} \text { idea }}=3.96 ; t=-.95, p=n s\right) .{ }^{1}$ Participants then completed questionnaires about the candidate's leadership potential using the same 3 item measure from study $2($ alpha $=.79)$.

\section{Results}

We used ANOVA to test our hypothesis that ratings of leadership potential would be lower in the creative relative to the useful condition controlling for sex of subject. Table 4 shows that the ANOVA results confirm a significant $2 \times 2$ interaction. Planned contrasts using a Bonferroni correction showed that when the charismatic prototype was activated, participants rated the candidate in the creative idea condition $(M=4.08)$ as having significantly higher leadership potential than the candidate in the useful idea condition $(M=3.41 ; t=-3.68, p<.01)$. Conversely, when the charismatic prototype was not activated, participants rated the candidate in the creative condition $(M=3.08)$ as having significantly lower leadership potential than the candidate in the useful condition $(M=3.60 ; t=-2.03, p<.05)$. 
Additional analyses employing the same competence and warmth scales $(\alpha>.80)$ from study 2 revealed no significant differences in perceptions of competence for the creative $(M=$ 4.76) and useful idea $(\mathrm{M}=4.60 ; t=1.13, p=n s)$, or warmth for the creative $(M=4.35)$ and useful idea conditions $(\mathrm{M}=4.31 ; t=.25, p=n s)$. Hence, expressing creative relative to useful ideas was not viewed negatively overall.

\section{General Discussion}

We began by noting that management scholars and the business elite are calling for a new vision of leadership, one that includes the ability to be creative. Drawing on prototype theories of creativity and leadership, we revealed that the most readily accessible prototype of leadership might not include creativity unless the charismatic leadership prototype is activated.

Creative solutions are defined as those that are both novel and useful; therefore we were careful to incorporate this two-part definition into our study designs. In both studies 2 and 3 idea usefulness did not significantly differ. Indeed, our results show that holding usefulness constant, idea creativity (usefulness and novelty) contributed to diminished leadership perceptions, but did not contribute to lower perceptions of competence. Therefore, our findings are not best explained by the simple fact that people dismiss potential leaders who suggest wildly irrelevant ideas, or that there is a negative halo associated with expressing creative ideas.

To overcome limitations associated with employing samples of undergraduates from the United States, we replicated the negative association between creative idea generation and perceptions of leadership potential using data from employees in India who had jobs which encouraged creativity. While this provides some evidence of the robustness and generalizability of our effects, no single sample can definitively demonstrate generalizability; hence additional cross-cultural research is clearly warranted. 
Despite these limitations, our findings make an important theoretical contribution. By integrating attributional theories of creativity (Elsbach \& Kramer, 2003; Kasof, 1995; Sternberg, 1985) and prototypical theories of leadership (Phillips \& Lord, 1981), we demonstrate that the expression of creative ideas can trigger impressions which, at least for leadership potential, are not automatically positive. Unless charismatic leadership is brought to mind or is chronically accessible, creativity might not necessarily signal leadership capability. Interestingly, our results suggest that, at least for our participants, their implicit and most readily accessible associations with leadership (those that arise naturally) are not compatible with creative idea expression. Much like the classic example of the a-typical flightless bird (Rosch, 1973), for some, recognizing the creative leader might require additional time and cognitive effort.

Our findings also suggest that organizations may face a bias against selecting the most creative individuals as leaders in favor of selecting leaders who would preserve the status quo by sticking with feasible but relatively unoriginal solutions. This may explain why in their analysis of scores of leaders, IBM's Institute for Business Value found that many leaders expressed doubt or lack of confidence in their own ability to lead through times of complexity (Kern, 2010). Our results suggest that if the dominant prototype of leadership favors useful, non-creative responses, that the senior leaders in the IBM study may have been promoted based on this prototypical perception of leadership and now find themselves in a world that has vastly changed, one that requires much more creative responses and thinking. Indeed, this bias in favor of selecting less creative leaders may partially explain why so many leaders fail (Hogan \& Hogan, 2001), and why so many groups resist change (Argyris, 1997), as the leaders selected may simply lack the openness to recognize solutions that depart from what is already known. 
Table 1

Study 1: Descriptive statistics all major variables, $N=291$

\begin{tabular}{|c|c|c|c|c|c|c|c|c|}
\hline & Mean & SD & 1 & 2 & 3 & 4 & 5 & 6 \\
\hline 1. Sex: $1=$ male, $0=$ female & .74 & .44 & & & & & & \\
\hline 2. Organizational Tenure & 5.00 & 2.95 & .02 & & & & & \\
\hline 3. Age & 31.67 & 6.10 & -.02 & $.64 * *$ & & & & \\
\hline 4. Education & 1.97 & .76 & .01 & $.21 * *$ & $.23 * *$ & & & \\
\hline 5. Intrinsic Motivation & 4.51 & 1.62 & -.02 & -.09 & -.03 & -.05 & & \\
\hline 6. Creativity & 3.79 & 1.43 & .01 & $-.12 *$ & -.09 & -.06 & $.33 * *$ & \\
\hline 7. Leadership Potential & 4.28 & 1.53 & $-.12 *$ & .04 & .06 & .06 & $.16^{*}$ & $-.12+$ \\
\hline
\end{tabular}


Table 2

Study 2: Descriptive Statistics All Major Variables, $n=97$

$\begin{array}{llll}\text { Mean } & \text { SD } & 1 & 2\end{array}$

1. Dyad Sex: $1=$ male, $0=$ female $.43 \quad .50$

2. Instructions: $1=$ Creative, $0=$ Useful $\begin{array}{lll}.53 & .50 \quad .04\end{array}$

3. Observers' Rating of Leadership Potential

\begin{tabular}{llll}
4.16 & 1.41 & -.06 & $-.20 *$ \\
\hline
\end{tabular}

$* \mathrm{p}<.05$

$* * \mathrm{p}<.01$ 
Table 3

Study 2: Analysis of Covariance for Perception of Leadership Potential

\begin{tabular}{lcccc}
\hline Source & $d f$ & $F$ & $\begin{array}{c}\text { Observed } \\
\text { Power }\end{array}$ \\
\hline Covariates & Dyad Sex & 1 & .27 & .00 \\
Main Effects & Instructions & 1 & $3.79 *$ & .04 \\
Error & & 93 & & \\
\hline Model $R^{2}$ & & .04 & & \\
Model $N$ & 97 & & \\
\hline$* p<.05 .{ }^{* *} p<.01$. & & & &
\end{tabular}


Table 4

Study 3: Analysis of Covariance for Perception of Leadership Potential

\begin{tabular}{|c|c|c|c|}
\hline Source & $d f$ & $F$ & $\begin{array}{c}\text { Observed } \\
\text { Power }\end{array}$ \\
\hline \multicolumn{4}{|l|}{ Covariates } \\
\hline Sex of Subject & 1 & 1.07 & .00 \\
\hline \multicolumn{4}{|l|}{ Main Effects } \\
\hline Charismatic Prototype Activation (CPA) & 1 & $7.06 * *$ & .04 \\
\hline Idea Type (IT) & 1 & .19 & .00 \\
\hline \multicolumn{4}{|l|}{ Interaction Effects } \\
\hline CPA X IT & 1 & $12.80 * *$ & .07 \\
\hline \multicolumn{4}{|l|}{ Error } \\
\hline Model $R^{2}$ & .12 & & \\
\hline Model N & 183 & & \\
\hline
\end{tabular}




\section{Footnotes}

1. The two conditions included: 1) "offer in-flight gambling with other passengers," or 2) "Charge for in-flight meals," to capture the creative and useful idea conditions respectively. 


\section{References}

Amabile, T. M. (1985). Motivation and creativity: Effects of motivational orientation on creative writers. Journal of Personality and Social Psychology, 48(2), 393-397.

Amabile, T. M. (1996). Creativity in context: Update to "The Social Psychology of Creativity." (Vol. 317). Boulder, CO, US: Westview Press.

Argyris, C. (1997). Initiating change that perseveres. American Behavioral Scientist, 40(3), 299309.

Cuddy, A. J. C., Fiske, S. T., \& Glick, P. (2007). The BIAS map: Behaviors from intergroup affect and stereotypes. Journal of Personality and Social Psychology, 92(4), 631-648.

Den Hartog, D., House, R., Hanges, P., Ruiz-Quintanilla, S., \& Dorfman, P. (1999). Culture specific and cross-culturally generalizable implicit leadership theories: Are attributes of charismatic/transformational leadership universally endorsed? The Leadership Quarterly, 10(2), 219-256.

Elsbach, K. D., \& Kramer, R. M. (2003). Assessing Creativity in Hollywood Pitch Meetings: Evidence for a Dual-Process Model of Creativity Judgments. Academy of Management Journal, 46(3), 283-301.

Goncalo, J. A., Flynn, F. J., \& Kim, S. H. (2010). Are two narcissists better than one?: The link between narcissism, perceived creativity and creative performance. Personality and Social Psychology Bulletin, 36, 1484-1495.

Grant, A. M. (2008). Does intrinsic motivation fuel the prosocial fire? Motivational synergy in predicting persistence, performance, and productivity. Journal of Applied Psychology, 93(1), 48-58. 
Hofmann, D. A., \& Gavin, M. B. (1998). Centering decisions in hierarchical linear models: Implications for research in organizations. Journal of Management, 24(5), 623-641.

Hogan, R., \& Hogan, J. (2001). Assessing leadership: A view from the dark side. International Journal of Selection and Assessment, 9(1-2), 40-51.

House, R. J., \& Howell, J. M. (1992). Personality and charismatic leadership. Leadership Quarterly. Special Issue: Individual differences and leadership: III, 3(2), 81-108.

Howell, J. M., \& Frost, P. J. (1989). A laboratory study of charismatic leadership. Organizational Behavior and Human Decision Processes, 43(2), 243-269.

Kasof, J. (1995). Explaining creativity: The attributional perspective. Creativity Research Journal. Special Issue: Attributional approach to creativity, 8(4), 311-366.

Kern, F. (2010). What Chief Executives Really Want. Bloomberg Businessweek.

Lord, R. G., Foti, R. J., \& de Vader, C. L. (1984). A test of leadership categorization theory: Internal structure, information processing, and leadership perceptions. Organizational Behavior \& Human Performance, 34(3), 343-378.

Mumford, M. D., \& Connelly, M. S. (1991). Leaders as creators: Leader performance and problem solving in ill-defined domains. Leadership Quarterly. Special Issue: Individual differences and leadership: I, 2(4), 289-315.

Mumford, M. D., Marks, M. A., Connelly, M. S., Zaccaro, S. J., \& Reiter-Palmon, R. (2000). Development of leadership skills: Experience and timing. Leadership Quarterly. Special Issue: Leadership skills, 11(1), 87-114.

Oldham, G. R., \& Cummings, A. (1996). Employee creativity: Personal and contextual factors at work. Academy of Management Journal, 39(3), 607-634. 
Phillips, J. S., \& Lord, R. G. (1981). Causal attributions and perceptions of leadership.

Organizational Behavior \& Human Performance, 28(2), 143-163.

Rosch, E. (1973). On the internal structure of perceptual and semantic categories. Cognitive development and the acquisition of language, 12, 308.

Rosch, E. H. (1978). Cognition and categorization. In R. E \& L. B. B (Eds.), Principles of Categorization (pp. 27-48). Hillsdale, NJ: Erlbaum.

Rothbard, N. P., \& Wilk, S. L. (2010). In the Eye of the Beholder: The Relationship between Employee and Supervisor Perceptions of Engagement and Their Effect on Performance. Working Paper, University of Pennsylvania.

Shin, S. J., \& Zhou, J. (2003). Transformational leadership, conservation, and creativity: Evidence from Korea. Academy of Management Journal, 46(6), 703-714.

Shin, S. J., \& Zhou, J. (2007). When is educational specialization heterogeneity related to creativity in research and development teams? Transformational leadership as a moderator. Journal of Applied Psychology, 92(6), 1709-1721.

Spencer, S., Zanna, M., \& Fong, G. (2005). Establishing a causal chain: Why experiments are often more effective than mediational analyses in examining psychological processes. Journal of Personality and Social Psychology, 89(6), 845.

Staw, B. M. (1995). Why no one really wants creativity. In C. Ford \& D. A. Gioia (Eds.), Creative Action in Organizations: Ivory Tower Visions and Real World Voices. Thousand Oaks, CA: Sage Publications, Inc.

Sternberg, R. J. (1985). Implicit theories of intelligence, creativity, and wisdom. Journal of Personality and Social Psychology, 49(3), 607-627. 
Sternberg, R. J. (2007). A systems model of leadership: WICS. American Psychologist. Special Issue: Leadership, 62(1), 34-42.

Tierney, P., Farmer, S. M., \& Graen, G. B. (1999). An examination of leadership and employee creativity: The relevance of traits and relationships. Personnel Psychology, 52(3), 591620.

van Knippenberg, D., van Knippenberg, B., De Cremer, D., \& Hogg, M. A. (2004). Leadership, self, and identity: A review and research agenda. The Leadership Quarterly, 15(6), 825856.

Yukl, G. (1989). Managerial leadership: A review of theory and research. Journal of Management. Special Issue: Yearly review of management, 15(2), 251-289. 